\title{
Risks associated with giving benzodiazepines to patients with acute neurological injuries
}

\author{
P R Eldridge, J A G Punt
}

\section{Intravenous}

diazepam is often given inappropriately and with great risk to neurosurgical patients with seizures
Intravenous benzodiazepines, especially diazepam, are widely recommended as first line treatment for status epilepticus but not for serial seizures. They penetrate the brain rapidly and thus quickly control seizures, although concentrations also fall quickly so that seizures may recur; the failure rate of the drugs is highest in patients with acute brain lesions. ${ }^{12}$ Intravenous benzodiazepines are also used as sedatives to allow a variety of invasive procedures including endoscopy.

The drugs have, however, been associated with decreased arterial oxygen concentrations and cardiovascular depression, ${ }^{3}$ which are particularly dangerous in patients with pre-existing neurological conditions. Intracranial pressure may be raised and autoregulation defective in such patients, and a drop in perfusion pressure combined with a reduction in blood oxygenation may produce irreversible neurological damage.

We have found that benzodiazepines are used inappropriately, often with risk to patients who have head injuries, spontaneous intracranial haemorrhages, or other acute neurological conditions.

\section{Case reports}

The table shows details of 10 patients with neurological conditions who presented to our unit over 18 months with complications after receiving intravenous diazepam. We report on three of these patients in further detail below.

Case 1-A 66 year old man who was an alcoholic and drank in excess of one bottle of spirits a day presented to a casualty department after falling in his bathroom and becoming unconscious. On arrival he was oriented in time and place. Skull radiographs showed a left parietal skull fracture. He then had three generalised seizures, which were self limiting; he recovered consciousness between each episode. He was given $10 \mathrm{mg}$ diazepam intravenously for each attack. He became unconscious again and had a respiratory arrest, which necessitated emergency ventilation and transfer to our unit. On arrival he was given a loading dose of phenytoin intravenously $(15 \mathrm{mg} / \mathrm{kg}$ at a rate not exceeding $1 \mathrm{mg} / \mathrm{kg} / \mathrm{min}$ ) followed by maintenance treatment $(300 \mathrm{mg} / 24 \mathrm{~h})$. A computed tomogram of his head was normal, and he was extubated without problem 24 hours later. No further fits were observed, and he made an uneventful recovery.

Case 2-A 6 year old girl was admitted to our unit after being hit by a car. She had received a head injury and became unconscious. She was observed to move her arms and legs, although she had an abnormal flexion response to pain. Computed tomography of the head showed intracerebral contusions and features of raised intracranial pressure. Hypothermia $\left(32^{\circ} \mathrm{C}\right)$ and hyperventilation (carbon dioxide partial pressure $3 \cdot 0-3 \cdot 5 \mathrm{kPa}$ ) with sedation were started to control the pressure. These measures were continued for three days and then reversed sequentially while intracranial pressure was monitored. After reversal of the sedation she was alert but unable to breathe or move her arms and legs. Radiographs of the cervical spine, a computed tomogram of the head, and results of magnetic resonance imaging were all normal. We diagnosed concussion of the high cervical cord, and over the next few days she recovered enough function of the spinal cord to be able to breathe and was gradually taken off the ventilator. She then had a self limiting generalised seizure, regaining consciousness, and was treated with diazepam $3.75 \mathrm{mg}$ intravenously. She had respiratory failure and required ventilation for a further 48 hours. She was then given loading and maintenance doses of phenytoin as described in case 1 and no further fits occurred.

Case 3-A 32 year old miner was struck on the head by a piece of machinery and became unconscious, but on arrival in the casualty department he responded to verbal commands. He was extremely agitated though breathing adequately. He was given $10 \mathrm{mg}$ diazepam intravenously so that an extensive scalp laceration could be sutured under local anaesthetic. His level of consciousness deteriorated rapidly and he developed respiratory failure, which required emergency intubation and ventilation. He was referred to our unit where computed tomography of the head showed frontal contusions and a chest radiograph showed some collapse of the left lung. He required ventilation for 48 hours and thereafter made a good recovery.

\section{Discussion}

We believe that the risks associated with giving benzodiazepines to patients with acute neurological disorders are insufficiently appreciated. As a result many patients are treated inappropriately, with a consequential increase in morbidity.

The man in case 1 had serial seizures, not status epilepticus, and benzodiazepines are not recommended for these. He received a very high dose of diazepam, which would have been dangerous in a

Details of 10 patients who had complications after receiving intravenous diazepam

Department of

Neurosurgery,

University Hospital,

Nottingham NG7 2UH

P R Eldridge, FRCS, registrar

J A G Punt, FRCs, consultant

Correspondence to:

Mr Eldridge.

Br.Med f 1990;300:1189-90

\begin{tabular}{cccllcl}
\hline \multicolumn{2}{c}{$\begin{array}{c}\text { Age } \\
\text { Case No (years) }\end{array}$} & Sex & \multicolumn{1}{c}{ Diagnosis } & Reason for giving diazepam & $\begin{array}{c}\text { Intravenous dose } \\
\text { of diazepam }\end{array}$ & \multicolumn{1}{c}{ Complication } \\
\hline 1 & 66 & M & Head injury & Repeated seizures & $30 \mathrm{mg}$ & Respiratory arrest \\
2 & 6 & $\mathrm{~F}$ & Head injury & Single seizure & $3.75 \mathrm{mg}$ & Respiratory arrest \\
3 & 32 & M & Scalp laceration & For suturing & $10 \mathrm{mg}$ & Respiratory failure \\
4 & 7 & M & Head injury & Decerebrate spasm & $5 \mathrm{mg}$ & Respiratory arrest \\
5 & 62 & $\mathrm{~F}$ & Subdural empyema & Continuous focal seizures & $5 \mathrm{mg}$ & Respiratory depression \\
6 & 75 & M & Chronic subdural head injury & Repeated seizures & $7 \cdot 5 \mathrm{mg}$ & Respiratory depression \\
7 & 3 & M & Head injury & Focal seizure & $7 \cdot 5 \mathrm{mg}$ & Respiratory arrest \\
8 & 71 & M & Head injury; colloid cyst & Single seizure & $5 \mathrm{mg}$ & Respiratory failure, loss of consciousness \\
9 & 29 & M & Head injury & Single seizure & $5 \mathrm{mg}$ & Respiratory failure \\
10 & 51 & M & Cerebellar haematoma & Agitation & $5 \mathrm{mg}$ & Ventilation, loss of consciousness \\
\hline
\end{tabular}


previously healthy person. Similarly, the girl in case 2 did not have status epilepticus. In this and the other cases it is difficult to prove that diazepam was the sole cause of respiratory failure, but as she was regaining consciousness after the fit and seemed to be breathing adequately before diazepam was given we believe that the drug was a major contributory factor. The man in case 3 was given diazepam when there wa no evidence of seizures.

Staff in neurosurgical units are often asked how to manage fairly simple procedures in agitated or totally uncooperative patients. If the problem must be dealt with urgently (as may be the case with a scalp laceration) the patient can be given either a loca anaesthetic and nursing care or a formal general anaesthetic by neuroanaesthetic techniques. Clearly, problems that are not urgent should be left until the patient's condition has improved.

In many cases emergency measures were taken for conditions that could have been dealt with less urgently. Delaying treatment would have ensured a higher standard of treatment and that other work in a busy hospital was not disrupted. For example, one woman (case 5) required prompt treatment for a subdural empyema; it was undesirable to have to provide treatment urgently as diazepam had put her on the brink of respiratory failure. A similar situation occurred in case 4 . The child required urgent intubation and ventilation but a crisis was created out of urgency when respiratory arrest occurred; a cardiorespiratory arrest team had to be called and had to abandon the work it was doing at that time.

In several patients blood gas estimations showed respiratory failure and high carbon dioxide pressure. This would result in a rise in intracranial pressure and account for the fixed dilated pupils in one patient (case 10) and possibly the need for ventilation in another (case 8). Respiratory problems occurred in all of our cases, and six patients required ventilation.

Although many factors may be blamed for the deterioration of the patients' condition, in all cases diazepam was given inappropriately and was likely to be harmful.

In such cases we control seizures with phenytoin; the success rate is equal to that obtained with diazepam, control is long lasting, and respiratory depression or depression of the level of consciousness is not a problem. Phenytoin is thought to act too slowly to be useful in controlling seizures. If, however, an adequate dose is given $(15-20 \mathrm{mg} / \mathrm{kg}$ at a rate not exceeding $1 \mathrm{mg} / \mathrm{kg} / \mathrm{min}$ ) seizures are controlled within 20 minutes in half of cases of status epilepticus due to an acute brain lesion. Peak phenytoin concentrations are achieved at the end of the infusion; or, well before brain damage from status epilepticus might be expected to occur. ${ }^{26}$ Care must be taken with the infusion as the vehicle is an irritant and the treatment has cardiological side effects. Severe acute toxic effects, however, are rare and noticed only when a loading dose is given to a patient whose serum concentration exceeds $20 \mu \mathrm{g} / \mathrm{l}$ (above normal limits). ${ }^{5}$ The risk of giving a loading dose to a patient known to be receiving phenytoin is therefore less than the risk of continued status epilepticus. In addition, phenytoin is recommended to be given at the same time as diazepam to prevent recurrent seizures when the diazepam wears off. Leppik et al have shown no difference between giving diazepam and phenytoin and giving phenytoin alone.

In conclusion, we believe that patients with head injuries or other acute neurological lesions who have status epilepticus or recurrent seizures can be managed effectively with phenytoin. Compared with benzodiazepines the risk of respiratory failure or loss of consciousness is reduced, and control of seizures is long lasting.

\footnotetext{
1 Browne TR. Status epilepticus. In: Browne TR, Feldman RG, eds. Epilepsy: diagnosis and management. Boston: Little, Brown, 1983:341-54.

Ramsay R, Hammond BJ, Perchalsk RJ, Wilder BJ. Brain uptake of phenytoin, phenobarbital and diazepam. Arch Neurol 1979;36:535-9.

3 Bell GD, Reeve PA, Moshiri M, et al. Intravenous midazolam: a study of the degre of oxygen desturation accurring during uper gastrintsinal degree of oxygen desaturation occurring durin

4 Eldridge PR, Hope DT, Yeoman P, el al. Influence of hypoxia on somatosensorv evoked potentials in intracranial hypertension [Abstract]. I Neurol sensory evoked potentials in intra

Neurosurg Psychiatry (in press).
Leppik IE, Patrick BK, Cranford RE. Treatment of acute seizures and statu epilepticus with intravenous phenytoin. Adv Neurol 1983;34:447-51

6 Wilder BJ. Efficacy of phenytoin in treatment of status epilepticus. Adv Neurol 1983;34:441-6.
}

(Accepted 8 December 1989

\title{
Scientifically Speaking
}

\section{When going to work makes you ill}

\author{
Bernard Dixon
}

"If earnest researchers go around with clip-boards, positively asking about these things, most people will say that they are a little under the weather at the moment, with a bit of a sore throat, a slight headache and a certain amount of tiredness," the late, much missed Henry Miller once said. "They will," he added, "be quite enthusiastic about revealing these medical facts to anyone who will listen - particularly if they are experts, and especially if they carefully write down what they are told."

Henry was talking about "suburban neurosis," a supposedly specific condition that had recently been identified among young housewives living on featureless housing estates. But his remarks could well apply (at least as a methodological caution for research workers) to several other maladies and syndromes that have erupted into the headlines from time to time.

Miller's dismissal certainly came to my mind when I first began to read claims, in newspapers and the scientific literature, about so called sick building syndrome. I had worked in at least one building that was blamed by some of its occupants for both winter sniffles and summer lethargy. But each of these complaints seemed to be amply explicable on conventional grounds. I was not, therefore, immediately converted even by carefully considered papers such as that published six years ago in the $B M \mathcal{F}$ in which Michael Finnegan and colleagues delineated the characteristic features of this modern malady.' Since then my scepticism has if anything been reinforced by successive reports attributing sick building syndrome to everything from mould spores in the air ducts to bacteria in the central heating, from radon gas seeping through the walls to invisible rays emanating from the VDU screen, from bad psychodynamics related to inept open plan office design to infrasound
Bernard Dixon, PHD, science 